\title{
Archivo, memoria y ficción en Nadie me verá llorar de Cristina Rivera Garza
}

\author{
Julia Érika Negrete SANdoval \\ juli7mas@hotmail.com
}

\begin{abstract}
Resumen: La estructura textual de Nadie me verá llorar, de Cristina Rivera Garza, está organizada a partir de la introducción de documentos reales tomados de las historias clínicas de algunos pacientes del manicomio La Castañeda, inaugurado en 1910 con motivo de la celebración del centenario de la Independencia de México. Este artículo explora el modo en que tal recurso pone en juego los conceptos de memoria y archivo, a partir de los cuales se relacionan el discurso histórico y el ficcional. El entrecruzamiento de ambos discursos y su función en el nivel de la construcción narrativa y de sentido, conducen, en el fondo, a una idea particular de la historia como disciplina y al cuestionamiento de su verdad en tanto discurso oficial de las instancias de poder.
\end{abstract}

Авstract: The structure of Cristina Rivera Garza's novel Nadie me verá llorar is organized with real documents taken from some patients' clinical stories at the mental hospital, La Castañeda, which was opened in 1910 to celebrate the Mexican Independence centenary. This paper explores the way in which the concepts of memory and archive are put in play to create a relationship between the historical and fictional discourses. The intersection of both discourses and its function in the level of the narrative construction and sense, bring, in the end, a particular idea of history as discipline and the question of its truth as an official discourse by the authority in power.

Palabras Clave: memoria, archivo, Historia, La Castañeda, México porfirista. KEYwORDS: memory, archive, History, La Castañeda, México porfirista.

¿Hacer Historia o hacer Literatura? Es quizás una interrogante que ha despertado el genio de buen número de escritores del siglo xx; y es que la relación entre estos dos tipos de escritura es tan estrecha, como difusos los límites que las separan. Tan es así que el desarrollo de teorías que tratan de definir la historia se han gestado a la par de esta suerte de "boom" de lo histórico convertido en literario. En esta línea se desplaza una de las escritoras mexicanas más destacadas en la actualidad, Cristina Rivera Garza (1964), quien, desde su formación como historiadora, entra en terrenos de la creación con una sensibilidad que ha sabido conjugar dos visiones: la del historiador y la del artista de la palabra. 
De esta doble perspectiva surge su primera novela, Nadie me verá llorar (1999), con la que consigue el beneplácito de la crítica y afianza su lugar dentro de las letras mexicanas.

En ella, la escritora convoca la historia de los últimos ańos del porfirismo y del México revolucionario y postrevolucionario, así como el acontecimiento particular del manicomio La Castańeda, inaugurado en 1910 con motivo de la celebración del centenario de la Independencia. Sobre ese cúmulo de pasado real se asienta el devenir de los protagonistas de la novela, Matilda Burgos y Joaquín Buitrago: una loca asilada en el manicomio - y que en otro tiempo fuera prostituta- $-y$ un fotógrafo morfinómano cuya vida carece de pasiones hasta que se reencuentra con Matilda.

Los juegos con el lenguaje y la estructura textual en Nadie me verá llorar se conectan con conceptos que han llamado la atención de los historiadores: memoria y archivo, si bien es cierto que el primero de ellos es también un tópico literario y que el segundo recientemente se ha incorporado al mismo ámbito. Aunque la novela de Rivera Garza ha sido ya objeto de numerosas aproximaciones críticas, pocas son las que abordan la relación entre el discurso histórico y el de la ficción, ${ }^{1}$ aunque, en efecto, la mayoría de ellas la señalan. Lo que aquí me interesa destacar de esa relación es, no obstante, el funcionamiento de las nociones de archivo y memoria y, a partir de ellas, acercarme al modo en que se realiza el cruce entre ambos discursos. Un elemento de singular im-

\footnotetext{
${ }^{1}$ Destaca a este respecto la investigación de Elena Alicia Magaña (2004), quien, desde esta perspectiva, realiza uno de los primeros acercamientos a la novela. Básicamente, su estudio parte de la tesis de resignificación de la historia que Rivera Garza lleva a cabo mediante el empleo de técnicas narrativas que integran el discurso de los marginados al discurso de la historia oficial para cuestionarlo. En esta misma línea entran los análisis de Claudia Macías (2006) y Claudia Parodi (2010). Si bien la mayoría de estudios dedicados a esta novela observan el tópico mencionado, las vertientes generales seguidas por la crítica apuntan, por un lado, al carácter subversivo de la novela en cuanto cuestionamiento de una época de la historia de México (Porfiriato y Revolución) y de su tradición literaria (naturalismo y narrativa de la Revolución), como muestran, entre otros, los artículos de Blanca Rodríguez (2003), Ana Rosa Domenella (2004), Robert Mckee Irwin (2005), Dolores Rangel (2008), Martha Munguía (2010) y Brian L. Price (2010). Por otro lado, en el rubro que engloba los temas de locura, prostitución y género, se encuentran los estudios de Elvira Sánchez Blake (2009), Sara Poot-Herrera (2010), Vinodh Venkatesh (2010), solo por mencionar algunos.
} 
portancia para dicho cruce se encuentra en el plano de la enunciación, esto es, en la incorporación de documentos verídicos intercalados en la narración y en la manera en que el narrador los dispone en el cuerpo del texto y reelabora lo dicho en ellos asumiendo distintas perspectivas. Todo esto conduce, en el fondo, a una idea particular de la historia como disciplina y al cuestionamiento de la verdad de su discurso en tanto palabra oficial de las instancias de poder.

\section{Documentos Y ReCUerdos: DOS FORMAS DE VISITAR EL PASADO}

La relación entre historia y literatura se ha vuelto un lugar muy visitado por la literatura contemporánea, no solo por la llamada novela históri$\mathrm{ca}$, sino por gran cantidad de textos que, si bien se ubican en el género de novela, presentan una tendencia generalizada a la hibridación discursiva, donde las formas del relato histórico entran en el universo de la ficción y, recíprocamente, amplían las dimensiones de sus discursos. ${ }^{2}$ En este contexto, la novela de Rivera Garza ejemplifica tal tendencia y, más aún, da constancia de una postura teórica respecto al quehacer histórico que subyace en su escritura: la visión del pasado desde la marginalidad, es decir, a partir de historias particulares de sujetos socialmente marginados y de los detalles de su vida cotidiana. ${ }^{3}$

\footnotetext{
${ }^{2}$ Cabe mencionar aquí la tesis de Julio Rodríguez-Luis (1997) sobre el enfoque documental de la literatura hispanoamericana del siglo xx, específicamente a partir de su segunda mitad, ya que la novela de Rivera Garza de algún modo se inscribe dentro de esta tendencia. El autor sugiere que dentro de la narrativa documental hay varias categorías, entre ellas "la novela documental", la cual se basa en "sucesos reales $\mathrm{y}$ en las relaciones de sus testigos, pero los incorporan no solo empleando procedimientos novelísticos [...] sino con la intención de crear una estructura novelística independiente de su origen documental", y su propósito es "crear un efecto artístico" (75, énfasis del texto). La novela documental es la más problemática de sus categorías, ya que no sigue el presupuesto básico según el cual toda narrativa documental "traduce la realidad tal cual es" (14), pues en cuanto ficción pone el acento sobre el aspecto inventivo de reelaboración de la realidad, muy aparte de cualquier intencionalidad ideológica o política.

${ }^{3} \mathrm{Si}$ bien es cierto que Nadie me verá llorar se apoya en ciertos aspectos del quehacer del historiador — como el trabajo sobre el documento y el privilegio de la perspectiva de la microhistoria - también subyace el diálogo con el pasado por el lado de la tradición literaria decimonónica y de principios del siglo xx, como atinadamente advierte Martha Elena Munguía (425-443) al destacar la importancia de la parodia que Rivera
} 
Nadie me verá llorar surge de la investigación que dio origen a la tesis doctoral de la autora; en ella se posiciona ante el hecho histórico, como señala Andrés Ríos Molina, del lado de la subalternidad y la observación de los rituales cotidianos, pues considera que desde ahí es posible abordar la construcción del Estado y cuestionar el cumplimiento de su proyecto modernizador (38). En la novela, sin embargo, la perspectiva es un tanto distinta, mucho más personal, aunque no se aleja de su origen, pues, como afirma la autora, su intención era hacer contemporáneo el pasado sin usurpar las voces de ese mundo que la inquietaba (2007: s. p.). Voces que, en la novela, corresponden no solo a Matilda y otros internos de La Castañeda; son también, aunque de modo distinto, las de Joaquín, Diamantina Vicario y Cástulo Rodríguez. Diamantina es el punto de contacto entre los recuerdos de Matilda y Joaquín; es la primera mujer de ambos, prototipo de la emancipación femenina. Del otro lado, en consonancia con el discurso de la ciencia positivista, está el doctor Eduardo Oligochea, quien, al facilitar el expediente de Matilda a Joaquín, los une en el presente.

Esos ecos del pasado construyen la complejidad de la narración, que se verifica en varios niveles: lo dicho, lo escrito, lo leído e interpretado, y lo no dicho por los personajes. El punto de partida es Joaquín Buitrago, el fotógrafo cuyo lente ha captado la imagen de Matilda años atrás en un burdel de Salto del Agua en la ciudad de México; la entrada en la novela se da a través de la lente de su cámara fotográfica; será él quien se encargue de desentrañar el pasado de Matilda en los expedientes del manicomio y en la memoria, la suya y la de ella. De la mano de un narrador en tercera persona que, de un capítulo a otro cambia su foco

Garza hace, entre otros aspectos, de la estética naturalista, en el sentido de que "el naturalismo se forja en los intentos de empatar arte y ciencia, de tal suerte que la novela reivindicaba para sí la objetividad, el análisis riguroso, de carácter científico, y orientaba su interés al examen de sujetos desplazados y socialmente problemáticos: alcohólicos, criminales, prostitutas" (428-429). En esta vertiente destaca también la idea de que la autora invierte el canon de la narrativa de la Revolución (Price: 111-133), en el que las historias de corte bélico, esencialmente masculinas, buscaban, más que una estética, la legitimación del poder y la reafirmación de una identidad nacional; de ahí que la novela de Rivera Garza sea la afirmación de que "la revolución como mito e historia ya no satisface las exigencias de la narración nacional" (131). Otra variante es la parodia a un periodo histórico, esto es, a la modernidad del México porfirista (Irwin: 71-82), representada en el nombre mismo del prostíbulo donde trabajó Matilda ("La Modernidad"), espacio clave en la novela. 
de atención, el lector se inmiscuye también en la historia de México a finales del siglo xix y comienzos del xx.

El texto abre con una pregunta de Matilda a Joaquín: "—¿Cómo se convierte uno en fotógrafo de locos?” (1999: 13). De modo que la memoria se presenta desde el comienzo como la entrada a ese pasado que llevó a los personajes a ser lo que son, aunque efectivamente es Matilda quien dará respuesta a la petición de él: "-Mejor dime cómo se convierte uno en una loca” (16). La alusión implícita a los actos de rememoración y narración que la mujer, desde su locura, realizará ante Joaquín coloca la perspectiva narrativa en el pasado que este irá reconstruyendo. Por lo demás, se advierte el doble papel de Joaquín quien, a modo de encarnación de la autora, busca en los archivos del manicomio y en bibliotecas los documentos que confirmen sus sospechas y le ayuden a reconstruir el misterio de una vida. Así, su búsqueda llega lejos al conjugar la narración personal de Matilda con los hallazgos en su expediente clínico.

Uno de los recursos que Rivera Garza utiliza para recrear la vida cotidiana en La Castañeda es la incorporación de partes de las historias clínicas de algunos internos; estos fragmentos, asentados dentro del texto en tipografía diferente, muestran la voz de los alienados, así como las observaciones de los médicos y el modo en que el sistema respondía a un orden venido de afuera, del aparato político, y no del conocimiento científico en el área de la psiquiatría. En este sentido, es viable decir que la perspectiva histórica se sostiene, por un lado, en la presentación de documentos verídicos, y, por el otro, en el relato de acontecimientos ocurridos en los ámbitos social, económico, político y cultural de la época. ${ }^{4}$ Sin embargo, este mismo recurso pone de manifiesto el artificio de la ficción, pues deja ver el juego imaginativo entre los niveles del relato, la historia o diégesis y la narración (enunciación). ${ }^{5}$ En este último

\footnotetext{
${ }^{4}$ Según Ríos Molina, Rivera Garza en su investigación aborda "la historia de La Castañeda desde una vertiente más cercana a la historia cultural: la vida cotidiana y su relación con la construcción del Estado moderno [...] La importancia de dichos detalles [los cotidianos] es que allí es posible detectar las trazas de esa modernidad tan prometida como evasiva" (38). Sin duda, al optar por esa perspectiva en su novela, la escritora hace coincidir realidades distintas de un mismo momento histórico y, así, pone en tela de juicio la hegemonía de la historia política y económica.

${ }^{5}$ Sigo la distinción que hace Genette en Figuras III entre historia (significado o contenido narrativo — diégesis), relato (significante o texto narrativo) y narración (acto na-
} 
nivel, destaca la forma que María Isabel Filinich llama "enunciación escrita" (117-122), representada por los textos que el narrador atribuye o no a un personaje pero que informan sobre la historia contada y sustituyen, en algunos casos, la verbalización del propio narrador o de los personajes.

El acto de lectura es otra forma de esta modalidad de la enunciación: el texto se puede presentar no solo como escrito o transcrito por el personaje, sino también como leído. Como ejemplo, en el segundo capítulo de la novela, la transcripción, en cursivas, de fragmentos de los libros de historia que Joaquín consulta en la Biblioteca Nacional para descubrir el pasado de Matilda alude al acto de lectura que él lleva a cabo. Al mismo tiempo que sirven para construir la genealogía de este singular personaje, tales textos informan sobre el México antiguo, concretamente acerca de la llegada del pueblo totonaca al Tajín y, posteriormente, sobre los avatares de esta gente por sobrevivir a la explotación del caciquismo porfiriano.

La escritura como enunciación se presenta no únicamente en los textos insertos o transcritos, sino también en las alusiones a los actos de lectura y escritura, que constituyen dos de las acciones más significativas entre los acontecimientos narrados: "Joaquín está tomando notas" (1999: 62), o más adelante: "El fotógrafo lee todos los libros. Las primeras noticias del Tajín llegaron al mundo en 1785" (62). En el caso de Matilda, mucho antes de que se presente el texto escrito por ella, la referencia al acto de escribir antecede a lo que vendrá al final: "Escribe. Escribe cartas. Escribe despachos diplomáticos. 'Mierda de mundo'. Escribe un diario. Todos sus papeles van a parar al expediente 6353 y ahí se quedan en los márgenes de los días y del lenguaje, como Joaquín, como el manicomio" (25). He aquí lo singular de este recurso en la novela de Rivera Garza: el texto escrito es el elemento introductor de la veracidad que sirve de apoyo tanto al contexto histórico que nutre y significa la diégesis como a la verosimilitud del relato en tanto ficción. A propósito de este tipo de enunciación, Filinich puntualiza: "La escritura como modalidad de verbalización de la historia remite, de una u otra manera,

rrativo productor); uso el término diégesis para evitar confusiones y repeticiones de la palabra "historia". Remito, asimismo, al concepto de enunciación que propone María Isabel Filinich, "representado por la relación entre el nivel del relato y el de la narración o situación narrativa”, a la que llama también enunciación ficcional (32). 
a la forma del documento, del texto que tienen una existencia aparte del acto narrativo de destinarlo como historia a un narratario. A la manera del documento histórico, puede presentarse como anterior al acto narrativo" (120).

Desde esta óptica, la noción de archivo se apoya en la lectura e interpretación de documentos que anteceden a la narración de la novela y se proyecta en la estructura del texto como ruptura, como el fragmento que introduce la voz de la historia y, de algún modo, la del otro. Para el historiador, la prueba documental representa una fuente primordial de conocimiento del pasado, en la medida en que de ella depende la reconstrucción de lo realmente ocurrido o, en palabras de Paul Ricoeur, de lo que "un día fue" (1996: 837). De ahí el valor de estos textos, sobre todo por su carácter de testimonio, en cuanto palabra individual, porque con ellos se evoca el acontecimiento histórico al mismo tiempo que se da a conocer su otra cara: la de lo vivido. ${ }^{6}$ Aunque las partes de los expedientes incluidos presentan modificaciones respecto del original, está patente el hecho de que cada texto aporta una significación particular de la experiencia de la historia y, en este sentido, conforman una memoria colectiva que, a su vez, convoca la imagen del archivo, almacén de retazos, como si este fuese otro tipo de memoria.

Por su parte, el trabajo de la ficción sobre el documento no está solo en la modificación de datos, sino que llega al nivel del lenguaje mismo. Desde el comienzo de la novela se observa la importancia que Rivera Garza reserva al trabajo con el lenguaje, concretamente con la escritura, ese cúmulo de signos que guardan la huella del pasado y cuyo valor depende de la calidad de la información que conservan así como del ojo lector que los interprete. No puede dejar de mencionarse el lenguaje de la fotografía como apoyo del texto escrito, o de la propia memoria, en cuanto es un soporte de imágenes que conservan

\footnotetext{
${ }^{6}$ En un artículo dedicado a elucidar la presencia de la historia en la ficción en Nadie me verá llorar, Claudia Macías Rodríguez reflexiona sobre el valor de los expedientes que Rivera Garza integra en la novela en tanto testimonios que no solo muestran la subjetividad de quienes cuentan su propia historia, sino que también llevan la marca de lo oficial al ser clasificados con un número y una descripción médica. Para la crítica, el empleo del testimonio apoya la narración de la historia de una vida y, de ese modo, se efectúa la reescritura de la historia en la ficción (2006).
} 
partículas de tiempo. ${ }^{7}$ En este sentido puede leerse el capítulo tres de la novela, "Todo es lenguaje", donde se encuentran intercalados algunos expedientes clínicos. Este capítulo nos coloca directamente en el terreno híbrido donde confluyen historia y ficción, y donde esta última cuestiona el valor de "verdad" de la primera. Aunque se trata de documentos verídicos, hay, como he señalado, información —los nombres, por ejemplo— que ha sido modificada; no obstante, estos no pierden su valor de prueba material al mismo tiempo que hacen evidente el artificio que estructura parte de la narración. Estos documentos, llamados historias clínicas, incluían el registro de los antecedentes familiares y de salud del enfermo, descripciones de síntomas, constitución física, comportamiento y observaciones del médico que entrevistaba al paciente. A pesar de la pretendida objetividad y orden de estos registros, lo único de que disponía la psiquiatría en el México porfirista era de un lenguaje impreciso: el de los locos, los de "adentro".

Los fragmentos de textos intercalados en la narración sugieren un recorrido que va desde el conjunto de documentos ordenados y resguardados por una institución hasta la materialidad del lenguaje fijado por la escritura que, a su vez, lleva la marca personal de quien escribe. En lo escrito queda la huella del pasado que el historiador tiene que descifrar. La preocupación por el lenguaje en la novela de Rivera Garza se inclina a poner en duda la calidad de su precisión en la ciencia, concretamente en la psiquiatría, cuyo léxico aún era incapaz de designar las afecciones mentales y orientarse adecuadamente en la interpretación de las manifestaciones verbales de la locura, como muestra la figura del doctor Eduardo Oligochea, médico de guardia de La Castañeda — uno de los personajes que transmiten la otra visión de la realidad, la de los estratos vinculados al poder, reproducción a menor escala de la estructura de este y sus proyectos de progreso y modernización-, quien es incapaz de conciliar el contenido de los expedientes con las descripciones médicas de los libros, porque "los maestros con los que empezó a explorar el laberinto de la mente hablan un idioma, y los enfermos recluidos dentro de los muros de La Castañeda, otro diferente" (1999: 87).

\footnotetext{
${ }^{7}$ De hecho, la autora reconoce haberse inspirando, precisamente, en la fotografía de una interna del manicomio: "A Matilda la encontré en una fotografía cuando yo realizaba mi investigación (de corte académico, aunque también de corte muy personal) en los expedientes del Manicomio General La Castañeda" (2007: s. p.).
} 
Las historias clínicas permiten apreciar que, más allá del carácter narrativo que, según Paul Ricoeur, ${ }^{8}$ comparten la historia y la ficción, se abre una brecha en el lenguaje: los testimonios sugieren la equiparación del lenguaje de la locura con el lenguaje poético, cuya verdad linda con territorios que no son ya los de la historia oficial sino los de una subjetividad que al dar su propia versión de la realidad, la re-crea. Las voces marginales que se escuchan en Nadie me verá llorar conducen al desentrańamiento de modos de vida que responden a un marco social determinado por un sistema de exclusión impuesto por las instancias del poder. Y es que, a fuerza de no ser escuchadas, se vuelven excesivas, incoherentes o, por fin, enmudecen. Con todo, tales narraciones legitiman la voz de los otros, los de "adentro" o, en todo caso, "los de abajo" — recordando los personajes de Azuela—, que pugnan por restituir una memoria: de grupo, de familia, individual — memorias que han sido desplazadas, olvidadas.

El archivo tiene un valor institucional, a diferencia de la memoria, que ha ganado la atención de la historia merced al testimonio, en tanto alternativa para acceder al conocimiento del pasado y a la construcción de una memoria colectiva. En este sentido, la novela de Rivera Garza, más que oposición entre archivo y memoria, deja ver la complementariedad de sus funciones tanto para la historia como para la literatura. Si bien pone al descubierto lo que Pilar Calveiro llama "la voluntad archivadora de todo poder" (30), permite que la voz, o al menos el eco, del personaje Matilda se escuche de principio a fin, aunque el privilegio de la palabra lo tenga el narrador. La memoria aparece, entonces, como una posibilidad de reelaborar continuamente el pasado y reformular el sentido del presente; como sugiere Calveiro, en tanto proviene de la experiencia directa, la memoria reabre continuamente el pasado y lo confronta con la huella fija del documento. Así, aunque se cuestione la infidelidad de la memoria por estar sujeta al olvido en la evocación del pasado, se le otorga, al mismo tiempo, la capacidad de verificar o refutar la pretendida verdad del acontecimiento histórico asentado en los discursos oficiales.

\footnotetext{
${ }^{8}$ Según Paul Ricoeur, historia y ficción tienen en común el cometido de contar un relato y, más aún, de participar en la construcción de la temporalidad humana mediante el acto de narrar. En relación con la estructura de la trama, el autor propone la relación entre la poética del relato y la teoría de la historia (1999: 158).
} 
Habría que agregar que esos documentos son también discursos que la novela ficcionaliza. La puesta en juego del documento puede ser vista, entonces, ya sea como recurso de enunciación o como una perspectiva más para ampliar la información significativa en el desarrollo de la diégesis. De este modo, se puede hablar de una ficción de archivo, tomando en préstamo el término "ficciones del Archivo" de Roberto González Echevarría, ${ }^{9}$ en la medida en que al mismo tiempo que evoca la imagen del archivo en su forma institucionalizada - por no decir que se funda en ella— es también un resguardo, si bien secundario, del documento, es decir, la novela misma se convierte en archivo.

En Nadie me verá llorar, la reproducción del documento histórico es la prueba que sustenta la existencia del personaje central, Matilda; pero es además la constatación de la institucionalidad del archivo, de su almacenamiento y resguardo, que es también de la ocultación y el olvido. Esta es, precisamente, la otra cara de la Historia, la que se ha pasado por alto, la que, en su momento, desmentía el triunfo del proyecto modernizador de Díaz, y que solo después de muchas décadas salió a la luz para entonces sí hacer historia.

Para González Echevarría hay dos figuras clave que representan, entre otras cosas, los huecos del archivo: muerte y vejez, las mismas que, en Nadie me verá llorar, ilustran la adopción de la memoria como posibilidad de historiar. Matilda y Joaquín, aunque aún no seniles, están ya despojados de toda esperanza, de algo que los vincule con el futuro; dedicados a la evocación y reconstrucción del pasado, esperan como único y último destino el silencio, la paz, o, en definitva, la muerte. A propósito de la misma idea, el autor comenta:

\footnotetext{
${ }^{9}$ Hay que precisar que, con "ficciones del Archivo", el autor se refiere a las "narrativas que siguen buscando la clave de la cultura y la identidad latinoamericana, por lo que caen en la mediación suministrada por el discurso antropológico [...] $\mathrm{Al}$ mismo tiempo que socavan las bases de la antropología, las ficciones del Archivo privilegian el lenguaje de la literatura en el que se refugian tanto la novela como la antropología. Es una literatura que aspira a tener una función similar a la del mito en las sociedades primitivas y que de hecho imita las formas del mito proporcionadas por el discurso antropológico" (238). Estas narrativas encontraron su mayor desarrollo en la denominada "novela de la tierra" y los ejemplos paradigmáticos son Los pasos perdidos de Alejo Carpentier y Cien años de soledad de Gabriel García Márquez. Aunque la novela de Rivera Garza roza con esta concepción, su construcción apunta hacia una asimilación mucho más explícita de la figura del archivo y su funcionamiento tanto para la escritura de la historia como de la ficción.
} 
Estas figuras oraculares son vínculos con el pasado y depósitos de conocimientos, como archivos vivientes. Pero sus recuerdos son incompletos y selectivos. La senilidad es una figura que representa los huecos en estos personajes de archivo. [...] Hay una extrańa facultad creadora en los recuerdos de estos personajes que es paralela a la forma en que se lleva a cabo la selección en el Archivo para crear la ficción, y que se encuentra en sus lapsos de memoria (249).

Para Matilda, la locura es una suerte de vejez prematura, por eso se hace más evidente el carácter imaginativo y, por lo tanto, dudoso de la memoria, y no obstante, por lo mismo, enriquece la recuperación del recuerdo puro. La enfermedad de Matilda está vinculada con los recuerdos, su logorrea no es otra cosa que el ansia de narrativizar, de dar orden y sentido a su pasado. $\mathrm{Y}$ es que, en efecto, al parecer, la memoria se vuelve más brillante antes de vaciarse; de ahí que estos personajes sean también una suerte de arca de conocimientos capaz de colmar tantos huecos. Matilda y Joaquín constituyen, de este modo, la revaloración del acto rememorativo que, con sus fallas y aciertos, llena los vacíos que el archivo ha dejado en la historia; con sus recuerdos imponen cierto orden, un orden poético, a la selección de los fragmentos archivados. De ahí que su función como figura de indagación y desentrañamiento del pasado que se hace presente sea fundamental.

Si bien las nociones de memoria y archivo incumben tanto al discurso histórico como al ficcional, según se ha visto, se podría decir que en la novela de Rivera Garza, la memoria funciona como una figura literaria a la que, por contraste, se colocaría la figura del archivo perteneciente al campo de la historia. Para esta última, la memoria es un concepto complejo que se ha incorporado en las últimas décadas como posibilidad de historiar, mientras que para la ficción funciona como un mecanismo de elaboración de la trama. En Nadie me verá llorar, el funcionamiento de ambas figuras corre paralelo: el documento encuentra su confirmación o refutación en el acto de rememorar que los personajes llevan a cabo. Para Joaquín no basta la lectura del expediente de Matilda, necesita escuchar su propia versión de los hechos, y solo de ese modo puede reconstruir la historia de su vida, y viceversa: no es suficiente escuchar sus historias desproporcionadas, requiere una prueba material que las confirme. Dicho de otro modo, la memoria llena los olvidos del archivo, y éste los de la memoria: en el recuerdo está el regis- 
tro de lo que el archivo pasó por alto, aunque, por desgracia, el testigo no siempre viva para contarlo.

\section{De la memoria personal a la historia oficial}

Marcada por la exclusión y la reclusión, Matilda encarna las voces de los socialmente marginados a principios del siglo xx: pobres, indígenas, mujeres, enfermos, locos. Si bien su llegada a la ciudad de México significó, al principio, la entrada al mundo del orden y el progreso, es revelador que su vínculo con la lucha de Diamantina y Cástulo por la causa obrera haya cambiado su percepción de la realidad hasta el punto de arrojarse de lleno sobre ella renunciando, sin importar las consecuencias, a las comodidades y la protección que le ofrecía la posición social de su tío Marcos. Este último, lo mismo que el doctor Eduardo Oligochea, representa algunos de los objetivos del proyecto modernizador del régimen de Porfirio Díaz, pero también su fracaso. Ante la oposición de estas dos perspectivas (la de los de arriba y la de los de abajo) se descubre la intención de la autora de entrar en los rituales cotidianos de quienes habitaron en La Castañeda, con el fin de "mostrarlos en su quehacer regular, ahí donde el poder y la falta de poder se entrelazaron para crear estrategias de sobrevivencia y no principios dogmáticos" (Rivera 2001: 62). Y es que este interés por el registro de la cotidianidad tiene que ver también con el "giro subjetivo" que ha signado buena parte de los discursos contemporáneos, en un afán de entrar en los recónditos espacios de la intimidad, donde se resguarda una verdad, si bien menos objetiva, más trascendente. $\mathrm{Al}$ respecto, desde la perspectiva de la sociología cultural - y en cierta coincidencia con la propuesta de González Echevarría - Beatriz Sarlo observa que, desde hace por lo menos tres décadas, la mirada de los historiadores y científicos sociales se ha desplazado hacia ámbitos un tanto ignorados hasta ese momento: "la brujería, la locura, la fiesta, la literatura popular, el campesinado, las estrategias de lo cotidiano" (17-18), para buscar en ellos los elementos que se oponen a la "normalización" de los discursos del poder, ya que en la voz de los marginados y de los individuos comunes se encuentra, justamente, su refutación. Esta es la postura que Rivera Garza asume como historiadora y narradora de ficciones: la de privilegiar las historias marginales y desde ahí reescribir y cuestionar la Historia. 
Sin embargo, en Nadie me verá llorar suena también la voz del discurso oficial de la época porfirista, particularmente en el personaje de Marcos Burgos, quien encarna la ideología positivista y, con ella, la seguridad de que el método científico sería la solución de todos los problemas sociales. Convencido de que la higiene y la educación transformarían a las capas sociales más bajas haciendo de sus integrantes mejores individuos, Marcos Burgos pone a prueba sus teorías en Matilda, solo para confirmar su error. Él pensaba que "todas las patologías estaban directamente relacionadas con la falta de higiene tanto física como mental del populacho. Si el régimen de verdad creía en el orden y el progreso, sostenía, tendría que empezar por hacer de la higiene no un derecho sino un deber ciudadano" (1999: 106). Esta fue la creencia que imperó durante el porfirismo, cuya propuesta modernizadora conjugó los esfuerzos del Estado y los conocimientos en materia de salud para convertir al país en "un espacio sano, cómodo y limpio, a sus habitantes en individuos saludables, trabajadores y de utilidad para el Estado" (Agostoni: 76). Pero quienes mantenían esta opinión pertenecían a la clase acomodada y distaban mucho de conocer a fondo los problemas reales que aquejaban no solo a la capital sino a todo el país. Esta actitud acentuaba un cierto desprecio por los pobres, quienes, según la opinión de aquéllos, eran el origen del desorden y la inestabilidad social (Zea 1968).

En tal contexto surge el Manicomio General de La Castañeda, uno de los grandes proyectos del porfirismo que, más que velar por la salud de los enfermos mentales, constituyó un medio de control y exclusión de individuos considerados un peligro para la sociedad. Ya que no había lineamientos claros que establecieran quiénes debían ser internados, el manicomio alojó a todo el que, por su comportamiento fuera de las normas, diera indicios de incapacidad para interactuar socialmente. Hubo casos de reclusión de personas sanas cuyo encierro no estaba debidamente justificado y, sin embargo, vivían por algún tiempo bajo el supuesto amparo de esta institución creada por el Estado. Tanto para Ríos Molina como para Rivera Garza, una postura política como esta coincide con la tesis de Michel Foucault, según la cual las instancias de poder crean mecanismos — prisiones, hospitales, manicomios, etc. - para controlar, vigilar y mantener en los límites de la disciplina las conductas anormales que atentan contra el deber ser que estas establecen (Ríos: 189-190). Así las cosas, ningún diagnóstico era lo suficientemente claro y comple- 
to para asegurar el estado metal de los internos, pese a que oficialmente fueran declarados dementes. La locura, pues, no tenía parámetros concretos para su estudio, más bien se definió en términos de la moral imperante y del afán de eliminar obstáculos para el progreso. Su lenguaje también era incoherente, como el de Matilda Burgos, excesivo y lleno de historias reales e inventadas o, de pronto, simplemente era silencio.

Aunque la locura de Matilda hace dudar de las historias que cuenta, supera el discurso de la historia oficial en la medida que, olvidada de sí misma y víctima del sistema, ignora lo que ha ocurrido a su alrededor: "Para Matilda, en cambio, la revolución se redujo a dos forasteros recopilando datos. Un suicidio. La falta de sonidos. Los dos anduvieron siempre en las orillas de la historia, siempre a punto de resbalar y caer fuera de su embrujo y siempre, sin embargo, dentro. Muy dentro" (176). Joaquín, el fotógrafo de locos, es el único que cree y comprende las historias de Matilda que Eduardo Oligochea considera meros inventos de su profusa imaginación.

Las teorías del tío Marcos fracasan con la partida de Matilda, víctima de la enajenación a que la induce la muerte de Diamantina y las injusticias que asolan la ciudad, ignoradas mientras estuvo bajo la protección y vigilancia de su tío. El cambio en Matilda introduce otros espacios de marginalidad donde lo cotidiano contradice una vez más los ideales de modernidad. Así, la primera gran dificultad que enfrenta es la falta de empleo y los bajos salarios. Pronto, la pobreza se impone cuando la mujer que le proporcionó un catre en un rincón de su cuarto de vecindad muere y Matilda tiene que hacerse cargo de los dos hijos de esta. Dicha situación introduce al personaje a otro espacio marginal: el prostíbulo.

En este punto de la narración hay un doble movimiento espacial: en el tiempo de la diégesis, adentro; en el del relato, afuera: "Es el 21 de marzo de 1921" y mientras Matilda y Joaquín abandonan La Castańeda, el adentro del prostíbulo "es la historia que Matilda recuerda en el tren que los lleva desde Mixcoac a la Ciudad de México. Fuera” (132-133). La oposición de espacios amplía el contraste entre presente y pasado, recuerdos y realidad, ficción e historia. En el interior del burdel la vida de Matilda se degrada cada vez más, pero al mismo tiempo gana en libertad y experiencia; está, sin embargo, a un paso de la locura. El nuevo trabajo de Matilda, ahora llamada La Diablesa, representa otro de los problemas sociales que el gobierno porfirista en decadencia intentó solucionar. 
Según Ríos Molina, entre las enfermedades mentales más comúnmente identificadas en la época se encontraban: demencias, imbecilidad, epilepsia, alcoholismo, neurosis y parálisis general progresiva. Esta última estuvo asociada, en la mayoría de los casos, con la sífilis y esta, a su vez, con la prostitución, de modo que

los doctores no dudaron en afirmar que la prostitución era la causa incuestionable de dicha afección, germen de la "degeneración" racial que impedía la consolidación de una nación moderna, sana y civilizada. Por lo tanto, era necesario mantener un control riguroso sobre las prostitutas y todos aquellos hombres que tenían sexo con ellas: alcohólicos, criminales, drogadictos y otros tantos "degenerados" (164).

Esta vigilancia estuvo asociada además con una visión de la feminidad moldeada desde antaño por una sociedad patriarcal convencida de la inferioridad de la mujer. Por eso, la prostitución, como la locura, se consideraba una enfermedad y se la vinculaba con la degeneración y la mala conducta. La prostituta, a fin de cuentas, observa Marcela Lagarde, es una "loca" (587). Muy a tono con esta opinión, Rivera Garza incorpora la referencia a una obra paradigmática de la época, Santa, de Federico Gamboa, en cuyas páginas la visión masculina de la sexualidad femenina resultaba irrisoria ante la realidad que enfrentaban las prostitutas en la ciudad de México.

En el burdel, Matilda encuentra en Ligia a su segunda Diamantina $y$, por fin, consuma el amor que no tuvo con la primera, pero esta también la abandona. Su soledad la hace renunciar a las noches de La Modernidad y la conduce al desierto de San Luis Potosí al lado de Paul Kamàck, un ingeniero estadounidense prendado de esas tierras secas y empeñado en explotar las minas de Real de Catorce. La revolución está en progreso; sin embargo, para ellos no hay afuera, la única realidad es el silencio y las ganas de borrar todo el pasado: adentro es afuera, conjugados en un mismo espacio. Tras el suicidio de Paul en la explosión de una mina, Matilda se desploma en el vacío de la memoria, en un pasado temporalmente perdido. En 1918 vuelve en sí; al contar los últimos sucesos de su vida se da cuenta de que su pasado se consumió en las mismas llamas que Paul, pues nadie da crédito a su historia. Su regreso a la ciudad de México es la única forma de escapar de la desolación del desierto. 
Al llegar a la capital, encuentra como único refugio el manicomio, donde se consuma su degradación, que es simultáneamente su triunfo, o mejor, el triunfo de la contradicción sobre la razón de la ciencia y la verdad de la historia oficial. Está otra vez adentro, sin esperar nada, hasta que se reencuentra con Joaquín. Es el tercer encuentro, y será el último. Salen juntos al mundo de afuera, donde todo ha cambiado y, no obstante, para ellos sigue siendo el mismo: "Matilda Burgos y Joaquín Buitrago se han perdido todas las grandes ocasiones históricas. Cuando la revolución estalló, ella estaba dentro de un amor hecho de biznagas y aire azul, y él en la duermevela desigual de la morfina" (175). Es 1921: un año antes el nuevo Estado, el posrevolucionario, había tomado la dirección de la política nacional, esta vez con la participación de las clases medias (Escalante: 254 y ss.).

En la casa de Santa María la Rivera Joaquín pasa horas escuchando las historias interminables de Matilda, sus recuerdos llegan a veces a borbotones, entonces no para de hablar hasta que regresa, otra vez, el silencio. Los días que pasan juntos ahí son la última puerta que ella abre al pasado, la misma que clausurará el futuro, ya que una vez despojada de los recuerdos volverá al encierro, al olvido de sí misma, a la locura: "Hablar, sin embargo, la ayuda a limpiarse, a borrar las trazas de gis en la pizarra verde del mundo. Pronto no quedará nada. Pronto podrá regresar a su refugio, a ese lugar sin puertas que Eduardo Oligochea denomina locura. Una afección mental. El silencio" (198).

En el transcurso de la novela se contraponen espacios que van uniendo una historia con la otra: la de adentro (Matilda, La Castańeda, el prostíbulo, Real de Catorce) y la de afuera (el país, la capital, la Revolución). Joaquín Buitrago funciona, en cierto sentido, como el punto de unión de ambos espacios y de las dos caras de la historia. Es, asimismo, la representación conjunta del historiar y el crear, la puesta en ficción de la figura compleja que conjuga al historiador y al artista, en quien recae la tarea de indagar, desde dos perspectivas, en el pasado para entender el presente; es el encargado de cotejar los recuerdos guardados en su memoria y en la de Matilda con la prueba documental; es en definitiva, el momento crítico que destaca el trabajo creativo del historiador más allá de su función interpretativa.

La rememoración se convierte para Matilda y Joaquín en una búsqueda, la de sí mismos. Él ha sido más afortunado; hijo de un reconocido médico, su nombre aún se pronuncia en los altos círculos sociales. 
El de ella, sin embargo, solo está en él y en los expedientes de La Castañeda, y a pesar de eso Matilda decide olvidarlo, borrar su identidad. Esta búsqueda del pasado de Matilda que comenzó el fotógrafo reúne dos momentos importantes de reconstrucción: rememoración e indagación. La memoria como búsqueda implica un acto de imaginación. El movimiento de retrospección de la memoria se asemeja al que lleva a cabo el historiador en el proceso de indagación, que tiene como exigencia, según Ricoeur, el archivo, y se entiende como "el movimiento mediante el que el historiador se somete al acontecimiento a través de la huella que deja en forma de archivo" (1999: 180). Mediante este movimiento entra la imaginación en el relato histórico, pues, según afirma el teórico, la huella tiene la estructura mixta del efecto-signo, esto es, en tanto marca de algo (efecto) precisa la deducción de una causa, mientras que como signo de algo presente que vale por pasado requiere de interpretación. Esta operación, que en primera instancia distingue al relato histórico del de ficción es, paradójicamente, uno de elementos que los acercan.

Un epígrafe de Maples Arce, extraído de la Hoja de vanguardia, en el último capítulo, "Vivir en la vida real del mundo", sitúa la historia nuevamente en 1921 y, al mismo tiempo que contextualiza con una referencia literaria que marca un momento decisivo en el arte a nivel mundial, exalta los cambios y la modernidad en auge de la ciudad de México. Esta nota reafirma el papel del hecho literario en la reconfiguración de la realidad en contraste con la investigación histórica, aunque ambos sean susceptibles de sustentarse en una prueba documental. Así pues, el cierre de la novela está constituido en gran parte por textos verídicos escritos por la interna que en la novela lleva el nombre de Matilda Burgos, personaje que es, al fin y al cabo, producto de la reelaboración imaginativa del relato de ficción. Ser contradictorio, cuya locura se define tanto por su logorrea como por el silencio, porque escribe y deja de escribir, por su exceso de recuerdos y por el olvido, Matilda hace coincidir su memoria con los mecanismos de selección de la historia oficial, para la cual registrar el pasado es recuperar de él solo lo que legitime el poder en turno. Más allá de esto, hay una voluntad autoral de rescatar a los olvidados, darles voz, poner en diálogo sus historias con la gran historia y, desde ese diálogo, sopesar su condición de verdad. 


\section{BibLIOGRAFÍA}

Agostoni, Claudia. "Salud pública y control social en la Ciudad de México a fines del siglo diecinueve", Historia y Grafia, Universidad Iberoamericana, 17 (2001): 73-97.

Calveiro, Pilar. "La memoria como resistencia: Memorias y archivos". De memoria y escritura, coord. Esther Cohen y Ana María Martínez de la Escalera. Ejercicios de memoria 3. México: Universidad Nacional Autónoma de México, 2002: 25-45.

Domenella, Ana Rosa. "Del canon a la parodia. Posible diálogo entre Santa y La Diablesa”. Santa, Santa nuestra, ed. Rafael Olea Franco. México: El Colegio de México, 2004: 287-302.

Escalante Gonzalbo, Pablo y otros. Nueva historia minima de México. México: El Colegio de México, 2009.

Estrada, Oswaldo, ed. Cristina Rivera Garza. Ningún crítico cuenta esto... México: Eón / The University of North Carolina at Chapel Hill / UC Mexicanistas, 2010.

Filinich, María Isabel. La vozy la mirada. México: Plaza y Valdés / Benemérita Universidad Autónoma de Puebla-Universidad Iberoamericana, 1997.

GonzÁlez EChevarría, Roberto. Mito y archivo. Una teoría de la narrativa latinoamericana. Trad. Virginia Aguirre Muñoz. México: Fondo de Cultura Económica, 2000.

Irwin, Robert Mckee. "La modernidad es un prostíbulo: Nadie me verá llorar de Cristina Rivera Garza". Territorio de escrituras. Narrativa mexicana del fin del milenio, coord. Nora Pasternac. México: Casa Juan Pablos / Universidad Autónoma Metropolitana, Unidad Iztapalapa, 2005: 71-82.

Lagarde, Marcela. Los cautiverios de las mujeres: madresposas, monjas, putas, presas y locas. $4^{a}$ ed. México: Universidad Nacional Autónoma de México, 2005.

Macías Rodríguez, Claudia. "Nadie me verá llorar: Huellas de la historia en la ficción”, Revista Iberoamericana 17 (2006): 193-213.

Magaña Franco, Elena Alicia. "Diálogos subversivos: ficción e historia en Nadie me verá llorar." Tesis de maestría. Universidad de Colima, 2004.

Munguía Zatarain, Martha Elena. "Cristina Rivera Garza. Memoria y subversión en Nadie me verá llorar". Doscientos años de narrativa mexicana. Siglo xx. Vol. 2, ed. Rafael Olea Franco, colaboradora Laura Angélica de la Torre. México: El Colegio de México, 2010: 425-443.

Parodi, Claudia. "Cristina Rivera Garza, ensayista y novelista: el recurso del método". Cristina Rivera Garza. Ningún crítico cuenta esto..., ed. Oswaldo Estrada. México: Eón / The University of North Carolina at Chapel Hill / UC Mexicanistas, 2010: 73-84. 
Poot-Herrera, Sara. "El paraíso de Matilda Burgos. Un refugio sin puertas". Cristina Rivera Garza. Ningún crítico cuenta esto..., ed. Oswaldo Estrada. México: Eón / The University of North Carolina at Chapel Hill / UC Mexicanistas, 2010: 85-110.

Price, Brian L. "Cristina Rivera Garza en las orillas de la historia". Cristina Rivera Garza. Ningún crítico cuenta esto..., ed. Oswaldo Estrada. México: Eón / The University of North Carolina at Chapel Hill / UC Mexicanistas, 2010: 111-133.

RANGel, Dolores. "Una lectura de la sociedad porfiriana en Nadie me verá llorar de Cristina Rivera Garza". Revista de Literatura Mexicana Contemporánea 15.37 (2008): 53-61.

Ricoeur, Paul. Tiempo y narración III. El tiempo narrado. Trad. Agustín Neira. México: Siglo XXI, 1996.

Ricoeur, Paul. Historia y narratividad. Trad. Gabriel Aranzueque, intr. Ángel Gabilondo y Gabriel Aranzueque. Barcelona: Paidós Ibérica / Universidad Autónoma, 1999.

Ríos Molina, ANDrés. La locura durante la Revolución Mexicana. Los primeros años del Manicomio General La Castañeda, 1910-1920. México: El Colegio de México, 2009.

Rivera Garza, Cristina. Nadie me verá llorar. México: Consejo Nacional para la Cultura y las Artes / Instituto Nacional de Bellas Artes / Tusquets Editores, 1999.

Rivera Garza, Cristina. "La vida en reclusión: cotidianidad y Estado en el Manicomio General La Castañeda (México, 1910-1930)”. Entre médicos y curanderos. Cultura, historia y enfermedad en la América Latina Moderna, ed. Diego Armus. Buenos Aires: Grupo Editorial Norma, 2003: 179-219.

Rivera Garza, Cristina. "Por la salud mental de la nación: vida cotidiana y Estado en el Manicomio General de La Castañeda, México 1910-1930”, Secuencia 51 (2001): 57-89.

Rivera Garza, Cristina. "Desde México para Corea. Entrevista a Cristina Rivera Garza”, Espéculo. Revista de Estudios Literarios (Universidad Complutense de Madrid). 35 (2007). 3 noviembre 2010. <http://www.ucm. es/info/especulo/numero35/crisrive.html>.

Rodríguez, Blanca. "Intertextualidades en Nadie me verá llorar de Cristina Rivera Garza". Revista de Literatura Mexicana Contemporánea 9.20 (2003): 105-115.

Rodríguez-Luis, Julio. El enfoque documental en la narrativa hispanoamericana. Estudio taxonómico. México: Fondo de Cultura Económica, 1997.

SÁNCHEZ-BlAKE, ElviRA. "Locura y literatura: la otra mirada". La manzana de la discordia 8 (2009): 15-23. 20 Sept. $2012<$ http://manzanadiscordia. univalle.edu.com>. 
Sarlo, Beatriz. Tiempo pasado. Cultura de la memoria y giro subjetivo. Una discusión. Buenos Aires: Siglo XXI, 2005.

VenkATESH, VinODH. “Transgresiones de la masculinidad: ciudad y género en

Nadie me verá llorar". Cristina Rivera Garza. Ningún crítico cuenta esto..., ed.

Oswaldo Estrada. México: Eón / The University of North Carolina at Chapel Hill / UC Mexicanistas, 2010: 135-154.

ZeA, Leopoldo. El positivismo en México: Nacimiento, apogeo y decadencia. México: Fondo de Cultura Económica, 1968. 